\title{
The AI-2/luxS Quorum Sensing System Affects the Growth Characteristics, Biofilm Formation, and Virulence of Haemophilus parasuis
}

\begin{abstract}
Bingzhou Zhang ${ }^{1}$, Xugang Ku ${ }^{1}$, Xiaoqian Zhang ${ }^{1}$, Yan Zhang ${ }^{2}$, Guo Chen ${ }^{1}$, Fangzhou Chen ${ }^{1}$, Wei Zeng ${ }^{1}$, Jing Li ${ }^{1}$, Ling Zhu ${ }^{1}$ and Qigai He ${ }^{1 *}$
\end{abstract}

${ }^{1}$ State Key Laboratory of Agricultural Microbiology, Division of Animal Infectious Diseases, College of Animal Sciences and Veterinary Medicine, Huazhong Agricultural University, Wuhan, China, ${ }^{2}$ College of Animal Sciences and Veterinary Medicine, Xinjiang Agricultural University, Urumqi, China

OPEN ACCESS

Edited by:

Guoquan Zhang,

University of Missouri, United States

Reviewed by:

Guogiang Zhu,

Yangzhou University, China

Zeliang Chen,

Shenyang Agricultural University,

China

Xuesong $\mathrm{He}$,

The Forsyth Institute, United States

${ }^{*}$ Correspondence:

Qigai He

he628@mail.hzau.edu.cn

Specialty section:

This article was submitted to Molecular Bacterial Pathogenesis,

a section of the journal

Frontiers in Cellular and Infection

Microbiology

Received: 11 October 2018

Accepted: 28 February 2019

Published: 19 March 2019

Citation:

Zhang B, Ku X, Zhang $X$, Zhang $Y$, Chen G, Chen F, Zeng W, Li J, Zhu L

and He Q (2019) The Al-2/luxS Quorum Sensing System Affects the

Growth Characteristics, Biofilm

Formation, and Virulence of Haemophilus parasuis.

Front. Cell. Infect. Microbiol. 9:62. doi: 10.3389/fcimb.2019.00062
Haemophilus parasuis ( $H$. parasuis) is a kind of opportunistic pathogen of the upper respiratory tract of piglets. Under certain circumstances, virulent strains can breach the mucosal barrier and enter the bloodstream, causing severe Glässer's disease. Many virulence factors are found to be related to the pathogenicity of $H$. parasuis strain, but the pathogenic mechanism remains unclear. LuxS/AI-2, as a kind of very important quorum sensing system, affects the growth characteristics, biofilm formation, antibiotic production, virulence, and metabolism of different strains. In order to investigate the effect of luxS/AI-2 quorum sensing system on the virulence of $H$. parasuis, a deletion mutant strain ( $\Delta$ luxS) and complemented strain (C-luxS) were constructed and characterized. The results showed that the luxS gene participated in regulating and controlling stress resistance, biofilm formation and virulence. Compared with wild-type strain, $\Delta$ luxS strain decreased the production of Al-2 molecules and the tolerance toward oxidative stress and heat shock, and it reduced the abilities of autoagglutination, hemagglutination, and adherence, whereas it increased the abilities to form biofilm in vitro. In vivo experiments showed that $\Delta$ luxS strain attenuated its virulence about 10-folds and significantly decreased its tissue burden of bacteria in mice, compared with the wild-type strain. Taken together, the luxS/AI-2 quorum sensing system in $\mathrm{H}$. parasuis not only plays an important role in growth and biofilm formation, but also affects the pathogenicity of $H$. parasuis.

Keywords: quorum sensing, $\boldsymbol{H}$. parasuis, luxS, biofilm formation, virulence

\section{INTRODUCTION}

Quorum sensing system (QS) was firstly discovered and described in two luminous marine bacterial species, Vibrio fischeri and Vibrio harveyi and it was reported to have regulated gene expression in response to increasing cell population density through autoinducer molecules (Nealson and Hastings, 1979). Based on the difference in autoinducers, quorum sensing system is classified into four types. The first type is luxR-I quorum-sensing system, in which LuxI is responsible for the production of the N-acyl-homoserine-lactone (AHL) autoinducer, and LuxR is activated by 
this autoinducer to increase transcription of the luciferase operon (Waters and Bassler, 2004). The second type is autoinducer peptide (AIP, a kind of short peptide signaling) quorum sensing system that exists in gram-positive bacteria (Waters and Bassler, 2004). The third type is luxS/AI-2 quorum sensing system which exists in approximately half of all the sequenced bacterial genomes (Waters and Bassler, 2004), and also in both gram-negative and positive bacteria. The last type is AI-3/epinephrine/norepinephrine quorum sensing system (Kendall and Sperandio, 2007). As a very important regulating system, quorum sensing system is associated with a diverse array of physiological activities and abilities, such as symbiosis, virulence, conjugation, antibiotic production, motility, sporulation, and biofilm formation (Miller and Bassler, 2001).

LuxS, as a kind of enzyme, plays an important role in activated methyl cycle (AMC) which is a pivotal metabolic pathway that serves to recycle homocysteine from S-adenosyl methionine (SAM) to maintain the de novo methionine biosynthesis. The secondary product (DPD) of this reaction undergoes spontaneous cyclization to form a mixture of different furanones including AI-2 accumulated in the culture supernatant (Hardie and Heurlier, 2008). The luxS/AI-2 quorum sensing system is reported to exist in different strains, such as Gamma and Betaproteobacteria, Lactobacillales, and Bacillales, especially in many Pasteurella strains (Sun et al., 2004; Rao et al., 2016). But, the function of quorum sensing system varies in different strains. For example, the deletion of luxS gene tends to significantly decrease bacterial biofilm formation, cell adhesion, hemolytic activity, and transcription levels of some virulence genes in Streptococcus suis strain (Wang et al., 2011). In $H$. influenzae, luxS gene can inhibit biofilm formation and increase virulence (Armbruster et al., 2009; Pang et al., 2018). However, luxS gene exerts a completely opposite function in A. pleuropneumoniae, compared with its function in $H$. influenzae strain (Li et al., 2008). Therefore, the functions of $\operatorname{luxS}$ gene in different strains are significantly different.

H. parasuis, a member of the Pasteurellaceae family, can cause Glässer's disease that is characterized by severe infection of the upper respiratory tract, polyserositis, meningitis, and arthritis in pigs (Liu et al., 2016). Although $H$. parasuis can lead to a severe disease and huge economic losses, its pathogenic mechanism has not been very clear, yet. $H$. parasuis can be classified into at least 15 serotypes. Among these serotype strains, serotype 1, $5,10,12,13,14$ strains are highly virulent, and serotype 2, 4, 15 strains are moderately virulent, and the rest are non-virulent (Jin et al., 2006).

It is very important to study the function of quorum sensing system and to reaveal its effect on growth characteristics and virulence of $H$. parasuis. However, so far, few reports about quorum sensing system in $H$. parasuis have been available. Therefore, this study is aimed to illustrate the function of quorum sensing system related gene luxS in $H$. parasuis by comparing, and evaluating the biological and virulent characteristics of wild-type HPS strain, luxS gene deletion mutant strain, and complemented strain.

\section{MATERIALS AND METHODS}

\section{Bacterial Strains, Plasmids, Primers, and Culture Conditions}

The bacterial strains, plasmids, and primers used in this study are listed in Table 1. Standard reference strain of $H$. parasuis serotype 2 (HPS2) was grown in Tryptic Soy Broth (TSB) or Tryptic Soy Agar (TSA) medium (Difco Laboratories, Detroit, MI, USA) supplemented with $10 \mu \mathrm{g} / \mathrm{mL}$ of nicotinamide adenine dinucleotide (NAD) and $5 \%(\mathrm{v} / \mathrm{v})$ inactivated cattle serum (T/V/S) (Zhejiang Tianhang Biotechnology, Zhejiang, China) at $37^{\circ} \mathrm{C}$. The culture condition of mutant strain ( $\Delta$ luxS) and complemented strain (C-luxS) are the same with that of wildtype strain with extra kanamycin $(50 \mu \mathrm{g} / \mathrm{mL})$ or gentamicin $(20 \mu \mathrm{g} / \mathrm{mL})$ (Sigma-Aldrich, Missouri, USA). Escherichia coli $\mathrm{DH} 5 \alpha$ was grown in Luria-Bertani medium at $37^{\circ} \mathrm{C}$. The luxS genes of 15 standard reference strains of $H$. parasuis strains were sequenced in GeneScript (Nan Jing, China).

\section{Homology Analysis of luxS Gene in Different Strains}

The luxS gene of $H$. parasuis serotype 2 was compared with some representative strains currently available from the National Center for Biotechnology Information (NCBI) through Basic Local Alignment Search Tool (BLAST) program with the default settings (Sun et al., 2004). The detailed luxS gene sequences of the reference strains were listed in Supplementary Data. Multiple sequence alignments were performed by the maximum likelihood algorithm method (bootstrap analysis with 1,000 replicates) with MEGA Version 6.06 (Chen et al., 2017).

\section{Construction and Verification of luxS Deletion Mutant and Complemented Strains}

All plasmids and primers used for the construction of luxS deletion mutant and complemented strains were listed in Table $\mathbf{1 .}$ The upstream (566 bp) and downstream (553 bp) fragments of luxS gene from HPS2 genome, and kanamycin resistance cassette (909 bp) from pSHK3 plasmid were amplified using primer pairs HPS-LuxS-u F/R, H-LuxS-d F/R, and Kan-F/R, respectively. The overlap extension method was used in these three fragments to construct a new fragment UKD (luxS upstream sequence, kanamycin resistance cassette sequence and luxS downstream sequence), then, the obtained UKD fragment was inserted into pk18mobsacB plasmid with EcoRI and $\mathrm{XbaI}$ restriction enzymes to generate recombinant plasmid pk18-UKD. The recombinant plasmid was introduced into HPS2 by natural transformation method as described in previous studies with a simple modification (Zhang et al., 2012; Wang et al., 2013; Zou et al., 2013). Briefly, $20 \mu \mathrm{L}$ of cAMP $(8 \mathrm{mM})$ was added to $20 \mu \mathrm{L}$ of recipient bacterial suspension in logarithmic phase $\left(\mathrm{OD}_{600}=\right.$ 0.9 ). Ten minutes later, $2 \mu \mathrm{g}$ of donor DNA plasmid was added to the bacterial mixture. Afterwards, the cells were added to T/V/S plate and incubated at $37^{\circ} \mathrm{C}$ for $6 \mathrm{~h}$. Subsequently, cells were transferred to a kanamycin selective plate. At last, the cells were incubated at $37^{\circ} \mathrm{C}$ for $48 \mathrm{~h}$. 
TABLE 1 | Characteristics of bacterial strains, plasmids, and primers used in this study.

\begin{tabular}{|c|c|c|}
\hline Strain, plasmid or primer & Characteristics and/or sequences & Source/References \\
\hline \multicolumn{3}{|l|}{ STRAIN } \\
\hline E. coli $\mathrm{DH} 5 \alpha$ & supE44 $\Delta$ lacU169 ( $\phi 80$ lacZ $\Delta$ M15) hsdR17 recA1 endA1 gyrA96 thi-1 relA1 $\Delta$ luxS & $\begin{array}{l}\text { Purchased from TaKaRa (Otsu, } \\
\text { Japan) }\end{array}$ \\
\hline V. harveyi BB170 & Al-2 reporter strain ( $\mathrm{Al}-1$ sensor ${ }^{-}, \mathrm{Al}-2$ sensor $\left.^{+}\right)$ & Bassler et al., 1997 \\
\hline V. harveyi BB886 & Al-1 reporter strain (Al-1 sensor ${ }^{+}, \mathrm{Al}-2$ sensor $\left.^{-}\right)$ & Bassler et al., 1997 \\
\hline H. parasuis 2 (HPS2) & Reference strain of serotype 2 & $\begin{array}{l}\text { Preserved in our lab Kielstein and } \\
\text { Rapp-Gabrielson, } 1992\end{array}$ \\
\hline 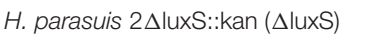 & luxS mutant of $H$. parasuis serotype $2, \mathrm{Kan}^{\mathrm{r}}$ & This study \\
\hline H. parasuis 2 2 luxS -luxS (C-luxS) & The complement of $H$. parasuis $2 \Delta$ luxS::kan containing $\mathrm{pSHK}_{3}-\mathrm{C}-\mathrm{luxS}, \mathrm{Kan}^{\mathrm{r}}, \mathrm{Gm}^{\mathrm{r}}$ & This study \\
\hline \multicolumn{3}{|l|}{ PLASMIDS } \\
\hline pK18mobsacB & Suicide and narrow-broad-host vector, $\mathrm{Kan}^{r}$ & Zhang et al., 2012 \\
\hline pK18- $\Delta$ luxS::kan & $\begin{array}{l}\text { A } 2064 \text { bp overlap fragment containing } \mathrm{Kan}^{r} \text {, the upstream and downstream sequences } \\
\text { of the luxS gene in pK18mobsacB, } \mathrm{Kan}^{r}\end{array}$ & This study \\
\hline $\mathrm{pSHK}_{3}$ & E. coli-H. parasuis shuttle vector, $\mathrm{Kan}^{\mathrm{r}}$ & Wang et al., 2013 \\
\hline $\mathrm{pSHK}_{3}-\mathrm{Gm}$ & $\mathrm{Kan}^{r}$ replaced with $\mathrm{Gm}^{r}$ (534 bp) in pSHK3, $\mathrm{Gm}^{r}$ & This study \\
\hline pSHK $3-\mathrm{C}-\mathrm{luxS}$ & A fragment containing the 660bp promoter and complete luxS ORF in pSHK3-Gm, Gm & This study \\
\hline \multicolumn{3}{|l|}{ PRIMERS } \\
\hline HPS-LuxS-F/R & $\begin{array}{l}\text { CCGGAATTCATGCCTTTACTAGATAGC; CGCGGATCCCTATGGATTTAGC; the amplified } \\
\text { sequence of luxS gene }\end{array}$ & This study \\
\hline H-LuxS-u F/R & $\begin{array}{l}\text { CCGGAATTCACCGCTTGTTAATACCGAGTCCACCATTG; } \\
\text { TTATCTTGTGCAATGAACGATTCTCCAATAAATA; } \\
\text { the amplified flank sequence upstream luxS coding sequence (566 bp) }\end{array}$ & This study \\
\hline Kan-F/R & $\begin{array}{l}\text { TATTATTGGAGAATCGTTCATTGCACAAGATAA; TTAGTTCCGTAGCAATAACAATTAAC } \\
\text { CAATTCTGATTAG; } \\
\text { the amplified sequence of kanamycin resistance gene ( } 909 \mathrm{bp})\end{array}$ & This study \\
\hline H-LuxS-d F/R & $\begin{array}{l}\text { CTAATCAGAATTGGTTAATTGTTATTGCTACGGAACTAA; } \\
\text { TGCTCTAGAACAAGCGGTAGCAGATACACGCCCAGC; } \\
\text { the amplified flank sequence downstream luxS coding sequence (553 bp) }\end{array}$ & This study \\
\hline HPS-16S-F/R & $\begin{array}{l}\text { GTGATGAGGAAGGGTGGTGT; GGCTTCGTCACCCTCTGT; } \\
\text { the amplified sequence of } 16 \mathrm{~S} \text { rRNA gene of } \mathrm{H} \text {. parasuis }\end{array}$ & Oliveira et al., 2001 \\
\hline C-LuxS-F/R & $\begin{array}{l}\text { CCGGAATTCATACAGAATITGATTGAAC; TGCTCTAGACTATGGATTAGCAATTTCTC; } \\
\text { the amplified sequence of luxS gene and its promoter sequence }\end{array}$ & This study \\
\hline hscA (0059)-F/R & $\begin{array}{l}\text { CGCCATTAACCTCTATTGACCC; CTTCCATATCTTGCTTCGCATT; the amplified flank } \\
\text { sequence upstream IUxS coding gene "HAPS_0059" }\end{array}$ & This study \\
\hline typA (0064)-F/R & $\begin{array}{l}\text { ATGAATTAGCGGTATCTCGTCC; TACTTCGTGCTGGTACTTGTCG; the amplified flank } \\
\text { sequence downstream IuxS coding gene "HAPS_0064" }\end{array}$ & This study \\
\hline
\end{tabular}

The complemented plasmid pSHK3-C-luxS was constructed by amplifying a 660 bp luxS open reading frame (ORF) and its promoter with primers C-LuxS-F/R. Subsequently, the amplicon was inserted into pSHK3-Gm plasmid derived from the framework of pSHK3-Kan with its kanamycin gene (909 bp) replaced by gentamicin gene (534 bp). The complemented plasmid was then introduced into the luxS deletion mutant by electroporation (2.5 kv, $5 \mathrm{~ms}$ ) (Wang et al., 2013).

To verify the construction results of the deletion mutant and complemented strains, luxS, gentamicin gene, kanamycin gene, upstream (HAPS_0059) and downstream (HAPS_0064) genes of luxS were amplified and verified by sequencing.

\section{Al-1 and Al-2 Bioluminescence Assays}

The assay was carried out based on the standard method described in the previous studies (Bassler et al., 1997; Wang et al., 2017) with some modifications. The bacteria for testing autoinducer product were grown in an orbital shaker at $30^{\circ} \mathrm{C}$, then supernatant of different time point (from 0 to $16 \mathrm{~h}$ ) was collected and cells were removed from the culture fluid by centrifugation at 5,000 $\times \mathrm{g}$ for $5 \mathrm{~min}$, followed by the passage of the culture fluids through $0.22 \mu \mathrm{m}$ pore size membrane filters. Meanwhile, the $\mathrm{OD}_{600}$ values at different time points were also measured. $V$. harveyi BB170 (AI-1 sensor-, AI-2 sensor+) and BB886 (AI-1 sensor+, AI-2 sensor-) as reporter strains to detect $\mathrm{AI}-1$ and $\mathrm{AI}-2$ molecules were grown overnight at $30^{\circ} \mathrm{C}$ in $A B$ medium. The cultured suspension was diluted 5,000 times in fresh $\mathrm{AB}$ medium. Subsequently, $90 \mu \mathrm{L}$ of the diluted cells were added to microtitre wells, and $10 \mu \mathrm{L}$ of cell-free culture fluid from the tested strains was added to each corresponding wells with a final concentration of $10 \%$. The supernatant of the overnight culture of $V$. harveyi BB170 or BB886 was used as the positive control, and $\mathrm{AB}$ medium was used as the negative control. The plates were incubated at $30^{\circ} \mathrm{C}$ in the incubator. 
Luminescence was measured every hour using a Synergy TM HT Multi-Detection Reader (Bio Tek Instruments, USA). AI-2 activity was quantified as relative luminescence units (RLU) at the time when the negative control produced the smallest amount of luminescence.

\section{Growth Characteristics of Different Strains of $\boldsymbol{H}$. parasuis}

The growth characteristics of wild-type strain HPS2, mutant strain $\Delta$ luxS, and complemented strain C-luxS were measured (Huang et al., 2016). Three kinds of strains were grown in $6 \mathrm{~mL}$ T/V/S medium overnight and then diluted in the same medium to an $\mathrm{OD}_{600}$ value of 0.8 . The $200 \mu \mathrm{L}$ of the diluted suspension was inoculated into $200 \mathrm{~mL}$ of fresh T/V/S medium, and then incubated at both $37^{\circ} \mathrm{C}$ and $40^{\circ} \mathrm{C}$, respectively in a shaker with $180 \mathrm{rpm}$. The $\mathrm{OD}_{600}$ value was determined using an Eppendorf Biospectrometer (Eppendorf, Hamburg, Germany) at $2 \mathrm{~h}$ intervals. The colony forming units (CFUs) were determined at $4 \mathrm{~h}$ intervals by counting colonies at the appropriate dilution obtained after a series of dilution. The experiments were performed in triplicate for three times.

\section{Stress Resistance Assays}

Stress resistance assays were performed based on a previously described method (Xie et al., 2013; Huang et al., 2016) with some modifications. The $\mathrm{OD}_{600}$ value of overnight cultivated $H$. parasuis wild-type strain HPS2, mutant strain $\triangle$ luxS, and complemented strain C-luxS was adjusted to 0.8. In the oxidative stress tolerance assay, $500 \mu \mathrm{L}$ of $1 \mathrm{M}$ hydrogen peroxide was added to $500 \mu \mathrm{L}$ of cell suspension and incubated at $37^{\circ} \mathrm{C}$ for $30 \mathrm{~min}$. In the heat-shock assay, cells were incubated in a $48^{\circ} \mathrm{C}$ water bath for $30 \mathrm{~min}$. Untreated cell suspensions of each strain after the incubation at $37^{\circ} \mathrm{C}$ for $30 \mathrm{~min}$ were used as a control in each experiment. Following incubation, the cultures were serially diluted by PBS, and their CFUs were determined by plate counting. The proportion of stress-resistant cells to control cells was calculated as $(\mathrm{CFU} / \mathrm{mL}$ in stress group / $\mathrm{CFU} / \mathrm{mL}$ in control group) $\times 100 \%$. Each assay was independently performed in triplicate for three times.

\section{Biofilm Formation Assay}

Biofilm formation assay was conducted on 96 wells microtiter plates (Thermofisher, USA) based on the methods described in previous studies (Stepanovic et al., 2000; Jin et al., 2006) with some modifications. The $\mathrm{OD}_{600}$ value of overnight cultivated strains was adjusted to 0.8 with the same treatment in the growth analysis assay. The $20 \mu \mathrm{L}$ of inoculum was added to each well which contained $180 \mu \mathrm{L}$ T/V/S medium, then was incubated at $37^{\circ} \mathrm{C}$ for different hours $(12,24,36,48$, and $60 \mathrm{~h})$. Each strain was tested in triplicate. After the time, the liquid of each well was removed with an injector and then the wells were washed three times with $200 \mu \mathrm{L}$ sterile PBS to remove loosely adherent cells. The remaining bacteria attached to wells were fixed with $100 \mu \mathrm{L}$ of methanol for $30 \mathrm{~min}$. After being dried in air, the wells were stained with $200 \mu \mathrm{L}$ of $1 \%$ crystal violet solution for $10 \mathrm{~min}$ at room temperature. Excess crystal violet was removed from the wells. Afterwards, the wells were washed to make sure the flowing water clean. Thereafter, the plates were dried in a $37^{\circ} \mathrm{C}$ incubator for $30 \mathrm{~min}$ and the dry cells were dissolved with $100 \mu \mathrm{L}$ of $33 \%(\mathrm{v} / \mathrm{v})$ glacial acetic acid, and the $\mathrm{OD}_{630}$ value of each well was measured with the same instrument as used in the detection of luminescence. All tests were carried out in sextuplicate for three times, and results were averaged. The wells that were not inoculated with bacteria were used as negative controls.

\section{Autoagglutination Assay}

Autoagglutination ability of $H$. parasuis strains was determined using a previously described method (Labandeirarey et al., 2010; Zou et al., 2013). Briefly, bacteria overnight cultivated to stationary phase were transferred into sterile tubes, $\mathrm{OD}_{600}$ of three kinds of strains was adjusted to the same value, and the tubes remained static at different environment temperatures (4, $25,37^{\circ} \mathrm{C}$ ). At last, the $\mathrm{OD}_{600}$ value was measured every hour in subsequent $24 \mathrm{~h}$. All tests were performed in triplicate for three times and the results were averaged.

\section{Hemagglutination Assays}

Overnight cultivated strains with their $\mathrm{OD}_{600}$ value adjusted to 0.8 were centrifuged at $6,000 \mathrm{rpm}$ for $5 \mathrm{~min}$ and resuspended in PBS. A $50 \mu \mathrm{L}$ of suspension and its 2 -fold serially diluted counterpart were added to a 96-well V-bottom Costar polypropylene plate (Fisher Scientific Co., USA) in sextuplicate. The $2 \%$ (vol/vol) suspension of erythrocytes derived from healthy swine was prepared using PBS. A $50 \mu \mathrm{L}$ of the erythrocyte suspension was then added to each well, and the last line of the wells was used as negative control only with erythrocyte suspension. The microtiter plate was gently agitated on a vortex mixer for $30 \mathrm{~s}$. Hemagglutination was recorded photographically after the incubation of the plate at $37^{\circ} \mathrm{C}$ for $30 \mathrm{~min}$ (Pearson et al., 2002). All of the above assays were performed in sextuplicate for three times.

\section{Adhesion Assays}

Adhesion assays were performed using porcine kidney epithelial cells (PK-15) (Zhang et al., 2012, 2014) following a previously described method (Vanier et al., 2004, 2006). Briefly, the cells $\left(5 \times 10^{5}\right)$ were seeded onto 24 -well tissue culture plates in Dulbecco's Modified Eagle's Medium (DMEM, Invitrogen) containing $10 \%$ heat-inactivated fetal bovine serum (Suero, Industria Argentina). After cells were cultured at $37^{\circ} \mathrm{C}$ in a humidified incubator at $5 \% \mathrm{CO}_{2}$ for $24 \mathrm{~h}$, the tissue culture cells were washed thrice with $\mathrm{PBS}$ and infected with approximately $10^{7} \mathrm{CFU} H$. parasuis. Culture plates were incubated at $37^{\circ} \mathrm{C}$ for up to $2 \mathrm{~h}$ to allow bacterial adhesion. Cells were rigorously washed five times with PBS to eliminate non-specific bacterial attachment and then incubated with $100 \mu \mathrm{L} 0.25 \%$ trypsin/EDTA at $37^{\circ} \mathrm{C}$ for $10 \mathrm{~min}$. After the incubation, the cells were resuspended from the bottom of every well. The cell suspensions with adherent bacteria were diluted 10 -folds and put onto TSA plates containing NAD and serum. The adhesion rate was calculated as the bacteria adhered to cells dividing the added bacteria $\times 100 \%$. All of the above assays were performed in triplicate for three times. 


\section{Determination of the $50 \%$ Lethal Dose $\left(\mathbf{L D}_{50}\right)$}

The virulence of wild-type strain HPS2, mutant strain $\Delta$ luxS, and complemented strain C-luxS was evaluated using 18-20 g female Balb/C mice (Li et al., 2017; Zhao et al., 2017) which were purchased from Huazhong Agricultural University animal center. A total of 130 mice were randomly divided into 13 groups with 10 mice in each group. The wild-type strain HPS2, mutant strain $\Delta$ luxS, and complemented strain C-luxS were cultured at $37^{\circ} \mathrm{C}$ until the last stage of logarithmic phase. Cells were collected from the culture fluid by centrifugation at 5,000 $\times \mathrm{g}$ for $8 \mathrm{~min}$, washed 3 times with PBS, and re-suspended in PBS. Then, the 3 types of strains were diluted with each strain corresponding to 4 concentrations: $9.63 \times 10^{7}, 2.08 \times 10^{8}, 4.47 \times 10^{8}$, and $9.63 \times 10^{8} \mathrm{CFU} / 0.5 \mathrm{~mL}$ (wild-type strain HPS2), $7.57 \times 10^{8}$, $1.55 \times 10^{9}, 3.34 \times 10^{9}$, and $7.57 \times 10^{9} \mathrm{CFU} / 0.5 \mathrm{~mL}$ (mutant strain $\Delta$ luxS), and $5.83 \times 10^{8}, 1.17 \times 10^{9}, 2.25 \times 10^{9}$, and 5.83 $\times 10^{9} \mathrm{CFU} / 0.5 \mathrm{~mL}$ (complemented strain C-luxS), respectively. The mice were raised for 3 days before experiment for their adaptation to the environment. The experimental mice were injected intraperitoneally (i.p.) with $0.5 \mathrm{~mL}$ of the suspension. The control mice were injected with $0.5 \mathrm{~mL}$ PBS. The number of surviving mice was recorded for 14 days after infection and the $\mathrm{LD}_{50}$ value was calculated according to Karber's method (Li et al., 2017; Zhao et al., 2017). Anesthetic was used on the remaining mice before they were executed. The research was approved by the Ethics Committee of the Faculty of Veterinary Medicine of the Huazhong Agricultural University with the protocol number as 42816300002256 . All procedures followed the instruction of the care and use of laboratory animals provided by Hubei provincial public service facilities.

\section{Determination of Viable Bacteria in Mice Organs}

A total of 48 female Balb/C mice were randomly and averagely assigned to four groups and used for assessing the presence of viable bacteria in infected mice organs. The experimental mice were injected i.p. with $0.5 \mathrm{~mL}$ of HPS2, $\Delta$ luxS, or CluxS $\left(10^{8} \mathrm{CFU}\right)$ strains, and the control mice were injected with $0.5 \mathrm{~mL}$ of PBS. The tissue samples $(0.1 \mathrm{~g} /$ organ $)$ of heart, liver, spleen, lung, and kidney were collected every day 1-4 days after infection and were fragmented into small pieces by using tissue homogenizer. After 10 -fold serial dilution with PBS, the $100 \mu \mathrm{L}$ of tissue mixtures at different dilution concentration were plated onto TSA plates and incubated at $37^{\circ} \mathrm{C}$ for $48 \mathrm{~h}$. The number of colonies were counted and presented as CFU/1 g. When the number of bacteria in every kind of tissue was counted, three plates were used at every dilutability and each experiment was performed in triplicate (Li et al., 2017; Zhao et al., 2017).

\section{Statistical Analysis}

The results are presented as the means \pm standard deviation (SD). The statistical analysis was performed using the twoway ANOVA in Graph Pad Prism 7.0 (GraphPad Software Inc., USA). The significant difference was defined as ${ }^{*} p<0.05$, and the various degrees of significant difference were designated as ${ }^{* *} p<0.01,{ }^{* * *} p<0.001,{ }^{* * * *} p<0.0001$, respectively.

\section{RESULTS}

\section{The Homology of luxS Gene in Different Strains}

The sequences of $\operatorname{luxS}$ orthologs were aligned and a phylogenetic tree was built from the alignment. Phylogenetic analyses were performed to evaluate the genetic relationship between $H$. parasuis and heterologous species strains (Figure 1) or the same family strains (Supplementary Table 1). The phylogenetic analysis results showed that $l u x S$ gene served as a distinction mark among different species. There were mainly three bigger branches in the phylogenetic tree including Gamma and Betaproteobacteria, Lactobacillales, and Bacillales (Figure 1). LuxS, as an important quorum sensing gene, also commonly existed in Pasteuriaceae including H. pittmaniae, H. influenzae, Pasteurella multocida, A. pleuropneumoniae, Mannheimia varigena, Bibersteinia trehalosi, and $H$. parasuis. The nucleotide homology across several common Pasteuriaceae strains ranged from 69 to $78 \%$ and protein homology ranged from 73 to $83 \%$ (Supplementary Table 1), which indicated a great functional similarity. Furthermore, the homology of luxS gene among 15 standard reference strains of $H$. parasuis was over 95\%, no matter at nucleotide or protein level (Supplementary Table 2).

\section{Construction and Verification of luxS Mutant Strain and the Complemented Strain}

The PCR identification results of HPS2, $\Delta$ luxS, and CluxS strains were shown in Supplementary Figure 1A 821 bp 16S rRNA fragment was identified in all three strains (Supplementary Figure 1A). The amplification of the fragments containing luxS gene, gentamicin gene, kanamycin resistance cassette sequence and UKD sequence produced the bands with different sizes (Supplementary Figures 1B-E), respectively. LuxS gene was found to exist in HPS2 and C-luxS strains. Gentamicin gene only existed in C-luxS strain. Kanamycin resistance cassette sequence existed in $\Delta$ luxS and C-luxS strains and UKD sequence. The different sizes of above-mentioned genes were observed in $\triangle$ luxS, C-luxS, and HPS2 strains. On the other hand, sequencing results indicated that plasmids, $\Delta$ luxS, and C-luxS strains exhibited no mutation. These results indicated the successful construction of $l u x S$ gene deletion mutant and its complemented strain.

In addition, the possible polarity effect resulting from wildtype HPS2, deletion mutant $\triangle$ luxS, and complemented strain C-luxS was examined by verifying the transcription of genes flanking luxS through RT-PCR (Supplementary Figure 1F). RTPCR results showed that both upstream gene (HAPS_0059) and downstream gene (HAPS_0064) all exited in cDNA and DNA of HPS2, $\Delta$ luxS, and C-luxS genomes. Therefore, it could be inferred that the transcription was not affected by the deletion of luxS gene. 


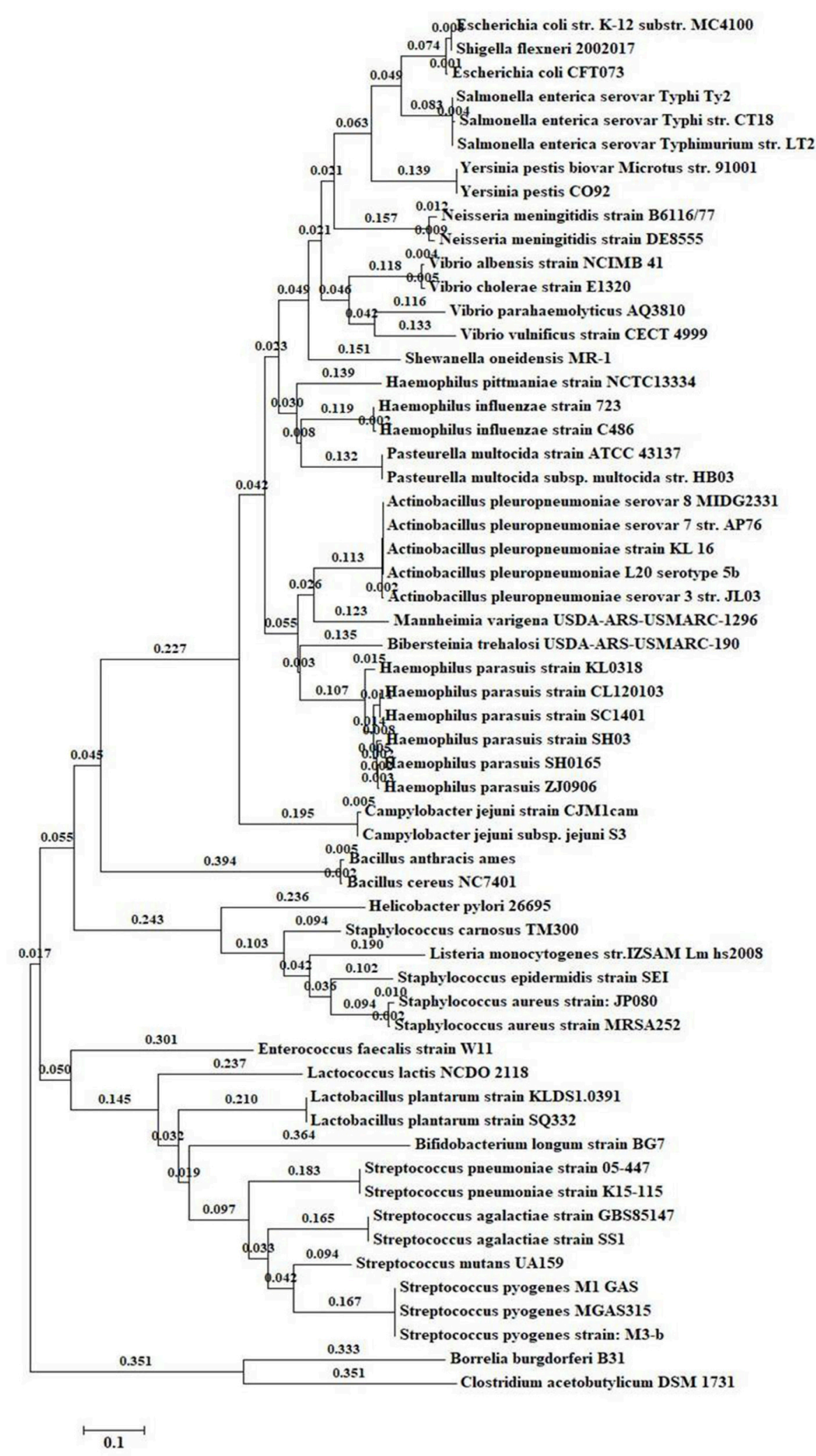

Enterobacteriales

Betaproteobacteria

Vibrionales

Psendomonas

Pasteurellales

Epsilonproteobacteria

Bacillales

Epsilonproteobacteria

Bacillales

Lactobacillales

Spirochete

Clostridia

FIGURE 1 | Phylogenetic tree of / uxS gene from the completely sequenced genomes in the KEGG genome database. The maximum likelihood algorithm method with the GTR nucleotide substitution model was used when constructed the phylogenetic tree (bootstrap analysis with 1,000 replicates). 


\section{Analysis of Al-1 and Al-2 Activity}

The ability of wild-type strain HPS2, deletion mutant $\Delta$ luxS, and complemented strain C-luxS to secrete AI-1 and AI-2 molecules was measured through BB170 and BB886 reporter strains. The result demonstrated that AI-2 molecule accumulation of was observed when BB170 was used as a reporter strain, while the similar accumulation was not observed in BB886 strain, suggesting that AI-1 molecule was not present in 15 kinds of standard serotype $H$. parasuis strains (no data available). Based on the luminescence values at different time points, it can be concluded that the strongest activity of AI-2 molecule in HPS2 was available after 12 -h cultivation in the shaker (Figure 2A). To verify whether AI-2 molecule was a molecule commonly existed in different serotype $H$. parasuis, the supernatant of 15 kinds of standard reference strains of $H$. parasuis was detected using BB170 strain. A very strong activity of AI-2 molecule was observed in almost all serotype strains (Figure 2B) except in serotype 8 strain. As seen in Figure 2C, AI-2 molecule showed much stronger activity in HPS2 strain than in $\Delta$ luxS strains and negative control, and AI-2 molecule was not available in $\Delta$ luxS strain. However, the complemented strain successfully recovered the activity of AI-2 molecule (Figure 2C).

\section{Growth Characteristics of HPS2, $\Delta$ luxS, and C-luxS Strains Under Different Conditions}

The growth characteristics of HPS2, $\Delta$ luxS, and C-luxS strains were investigated at 37 and $40^{\circ} \mathrm{C}$, respectively. The results showed that the growth rate of HPS2 and $\Delta$ luxS strains was almost the same, while the growth of C-luxS strain was about $2 \mathrm{~h}$ later than that of wild-type and deletion mutant strains at $37^{\circ} \mathrm{C}$, and the largest $\mathrm{OD}_{600}$ value of these three strains was almost the same. It took about $4 \mathrm{~h}$ for all three kinds of strains to enter logarithmic phase, while it took $12 \mathrm{~h}$ for HPS2 and $\Delta$ luxS strains to reach the stationary phases and $14 \mathrm{~h}$ for C-luxS strain. After about $18 \mathrm{~h}$ (HPS2 and $\Delta$ luxS strains) or $20 \mathrm{~h}$ (CluxS strain) of incubation, the $\mathrm{OD}_{600}$ value of these 3 strains decreased significantly as time went on (Figure 3A). The cell counting results showed that three types of strains had almost the same number of viable cells, At $12 \mathrm{~h}$, the highest CFU value was available for three strains: $2.25 \times 10^{9} \mathrm{CFU} / \mathrm{mL}$ for HPS2 strain, $3.15 \times 10^{9} \mathrm{CFU} / \mathrm{mL}$ for $\Delta$ luxS strain, and 2.01 $\times 10^{9} \mathrm{CFU} / \mathrm{mL}$ for C-luxS strains, respectively (Figure $3 \mathrm{~B}$ ). This study found that these 3 strains displayed a significantly different growth characteristics at $40^{\circ} \mathrm{C}$, that the growth of HPS2 was much faster than that of other 2 strains at $37^{\circ} \mathrm{C}$, and that the growth of $\Delta$ luxS and C-luxS strains was inhibited (Figure 3C) at $40^{\circ} \mathrm{C}$.

\section{Stress Resistance Results}

HPS2, $\Delta$ luxS, and C-luxS strains were exposed to various stress conditions, including heat shock and oxidative stress. When cells were treated in a $48^{\circ} \mathrm{C}$ water bath for $30 \mathrm{~min}$, the survival rate of $\Delta$ luxS strain $(48.1 \%)$ was obviously lower than HPS2 strain $(70.1 \%)(p<0.05)$. C-luxS strain $(68.1 \%)$ showed a similar survival rate to HPS2 strain (Figure 4A).
Similar pattern of survival rate was also found in oxidative stress assay. When cells were treated with $500 \mathrm{mM}$ hydrogen peroxide for $30 \mathrm{~min}$ at $37^{\circ} \mathrm{C}$, about $85 \%$ bacteria of $\Delta$ luxS strain were killed, but about $40 \%$ bacteria of HPS2 strain $(p<0.01)$ and $25 \%$ bacteria of C-luxS strain $(p<0.05)$ survived (Figure 4B). Taken together, these findings suggested an important role that $l u x S$ gene played in responding to various environment changes.

\section{Biofilm Formation in $\boldsymbol{H}$. parasuis enhanced by LuxS Mutant Strain}

To investigate the differences in biofilm formation among wildtype strain HPS2, deletion mutant $\triangle$ luxS, and complemented strain C-luxS under the same culture conditions, biofilm formation was quantitatively analyzed using microtiter plate assay at different time points. At the beginning of the first $12 \mathrm{~h}$, no biofilm formation was observed at the bottom of microtiter plates. However, after $24 \mathrm{~h}$ of cultivation in T/V/S medium, an obvious biofilm formation was observed in HPS2, $\Delta$ luxS and C-luxS strains, and at $36 \mathrm{~h}$, the largest amount of biofilm was observed. A significant difference in biofilm formation was found between HPS2 and $\triangle$ luxS strains, suggesting that $\triangle$ luxS strain could enhance biofilm formation ability from 24 to $60 \mathrm{~h}$ $(p<0.01)$, and that no significant difference in the biofilm formation ability was observed between C-luxS and HPS2 strain, so the complemented strain can restore biofilm formation ability to wild-type strain levels (Figure 5).

\section{Significantly Decreased Autoagglutination Ability of $\Delta$ luxS Mutant Strain}

The autoagglutination ability of HPS2, $\Delta$ luxS, and C-luxS strains were measured under different conditions. Based on the data, it can be concluded that the autoagglutination ability of $\Delta$ luxS and C-luxS strains was obviously weaker than that of HPS2 strain at 4,25 , or $37^{\circ} \mathrm{C}$. The difference in autoagglutination ability between HPS2 and $\triangle$ luxS strains became increasingly obvious with temperature declining from 37 to $4^{\circ} \mathrm{C}$. At $37^{\circ} \mathrm{C}$, the difference in autoagglutination ability between HPS2 and $\Delta$ luxS strains was observed after about $3 \mathrm{~h}$ of culturation in an incubator. Later, autoagglutination ability was partially recovered in C-luxS strain (Figure 6A1). However, at $4^{\circ} \mathrm{C}$ and at $25^{\circ} \mathrm{C}, \mathrm{HPS} 2$ and $\triangle$ luxS strains displayed a significant difference in autoagglutination ability after $1 \mathrm{~h}$ of culturation, and the partial recovery phenomenon was only found after $12 \mathrm{~h}$ of culturation (Figures 6B1, C1). In summary, HPS2 and $\triangle$ luxS strains displayed a significant difference in the autoagglutination ability at the first hour $\left(4\right.$ and $\left.25^{\circ} \mathrm{C}\right)(p<0.001)$ or the third hour $\left(37^{\circ} \mathrm{C}\right)(p<0.001)$ post culturation. On the other hand, an autoagglutination phenomenon was directly observed, when the strains were cultured at 4,25 , and $37^{\circ} \mathrm{C}$ at the 12 th h, respectively (Figures 6A2, B2, C2).

\section{Decreased Hemagglutination Ability of $\Delta$ luxS Strain}

To examine the hemagglutination ability of HPS2, $\Delta$ luxS, and C-luxS strains, porcine red blood cells were used to detect 

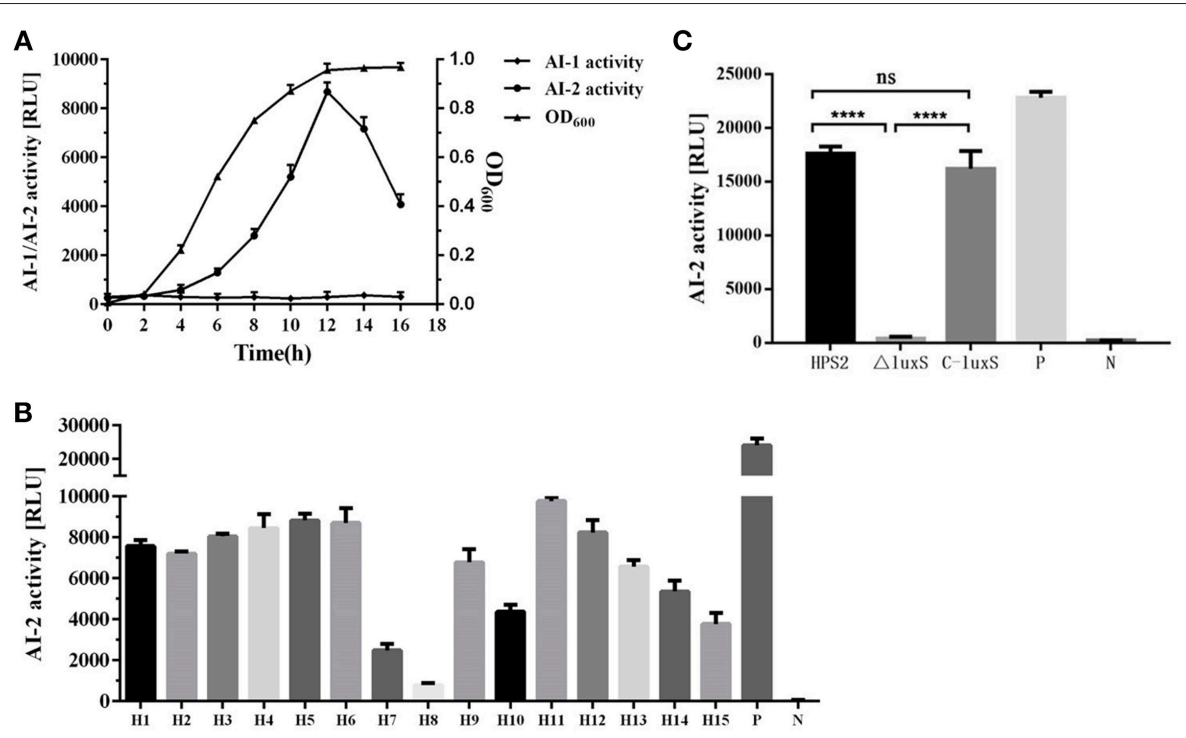

FIGURE 2 | The activity of Al-1 and Al-2 molecules in wild-type strain HPS2, deletion mutant $\Delta$ luxS and complemented strain C-luxS was measured through BB170 and BB886 reporter strains. (A) The luminescence value of supernatant and $\mathrm{OD}_{600}$ value of HPS2 at different time points $(0,2,4,6,8,12,14,16 \mathrm{~h})$. (B) The ability of H. parasuis serotype 1-15 to secrete Al-2 molecule. $\mathrm{H} 1-\mathrm{H} 15$ represent $H$. parasuis from serotype $1-15$, respectively. $\mathrm{P}$ represents positive control, $\mathrm{N}$ represents negative control. (C) The luminescence value of Al-2 molecules in the supernatant of HPS2, $\Delta$ luxS, and C-luxS strains. P represents positive control, $\mathrm{N}$ represents negative control. In these three independent experiments, the supernatant of $V$. harveyi BB170 $(\mathrm{V}$. h) was used as the positive control, and sterile AB medium (AB) was used as the negative control. The supernatant of HPS2, $\Delta$ luxS, and C-luxS strains were collected when the $\mathrm{OD}_{600}$ value reached 0.8. The incubation time of BB170 reporter strain was $5 \mathrm{~h}$. All of the above assays were performed in triplicate for three times. Bars represent the mean \pm standard deviation of three independent experiments. Statistical analyses were performed using the two-way ANOVA. ${ }^{\star \star \star \star} p<0.0001$ represents the highest degree of significant difference, and ns means no statistic significance.
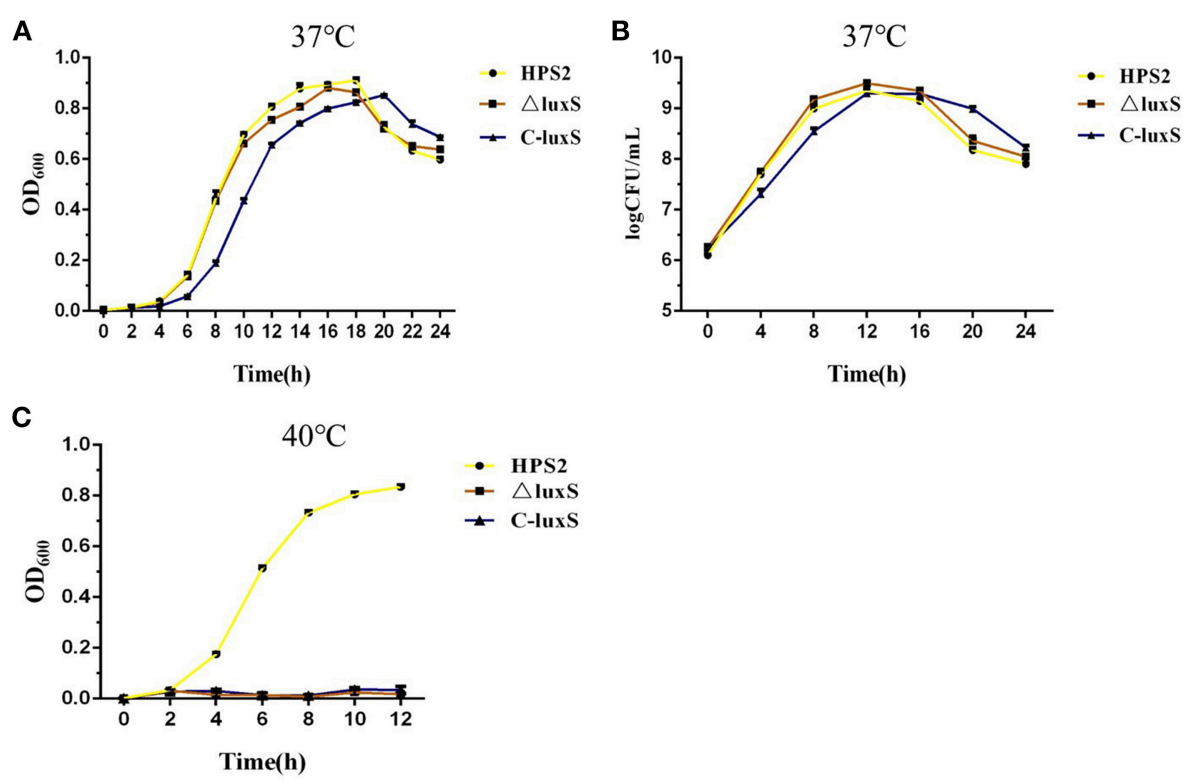

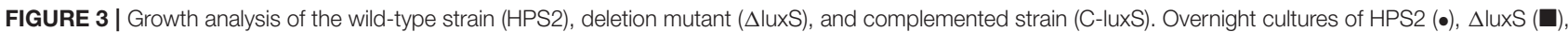
and C-luxS $(\mathbf{\Lambda})$ strains were diluted in TN/S medium and then incubated at either $37^{\circ} \mathrm{C}(\mathbf{A}, \mathbf{B})$ or $40^{\circ} \mathrm{C}(\mathbf{C})$. Bacterial growth was monitored by measuring optical density at $600 \mathrm{~nm}(\mathbf{A}, \mathbf{C})$ and viable cells at multiple time points (B). The dots represent the mean value of three replicates, and error bars indicates standard deviations.

hemagglutination titer. The hemagglutination titer of HPS2 strain was found to be $2^{5}$, in contrast, no hemagglutination ability of $\Delta$ luxS and C-luxS strains was observed, even if $10^{8} \mathrm{CFU}$ bacteria were added (Figure 7). Therefore, it could be inferred that the decrease in hemagglutination ability of HPS2 strain might be attributed to the deletion of luxS gene. 

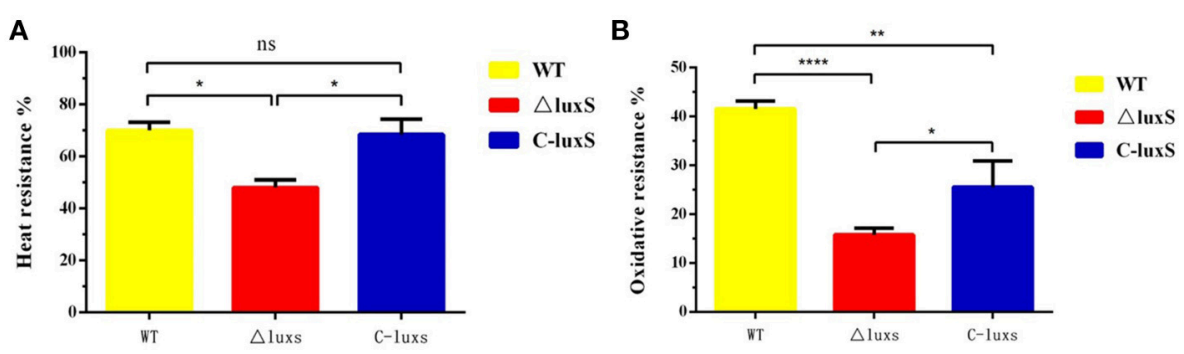

FIGURE 4 | Analysis of the stress tolerance of the HPS2, $\Delta$ luxS, and C-luxS strains. Overnight cultured bacteria were diluted with $\mathrm{OD}_{600}$ value adjusted to 0.8 . The $500 \mu \mathrm{L}$ of each cell suspension was incubated in a $48^{\circ} \mathrm{C}$ water bath for $30 \mathrm{~min}(\mathbf{A})$ or treated with $500 \mu \mathrm{L}$ of $1 \mathrm{M}$ hydrogen peroxide (B) at $37^{\circ} \mathrm{C}$ for 30 min, respectively. All of the above assays were performed in triplicate for three times. Bars represent the mean \pm standard deviation of three independent experiments. Statistical analyses were performed by using the two-way ANOVA. ${ }^{\star} p<0.05,{ }^{\star \star} p<0.01$, and ${ }^{\star \star \star \star} p<0.0001$ represent increasing degrees of significant differences, respectively, and ns means no significant difference.

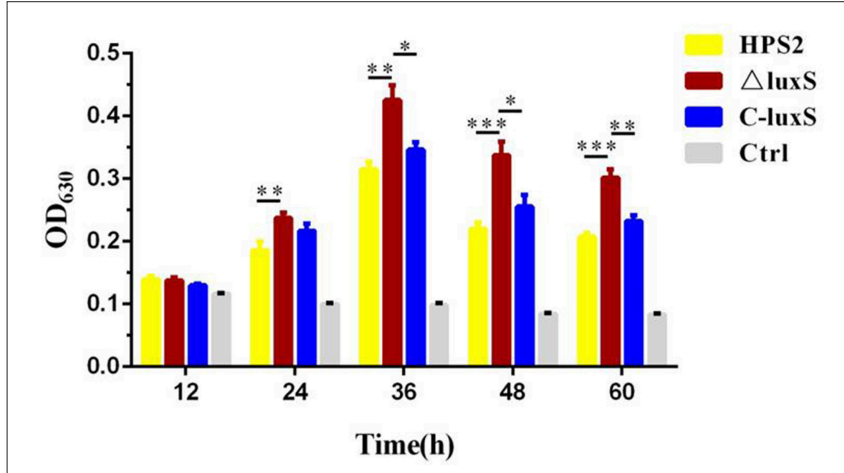

FIGURE 5 | Biofilm formation ability of HPS2, $\Delta$ luxS, and C-luxS strains at different time points. Biofilm formation was determined by measuring the $\mathrm{OD}_{630}$ value of dissolved crystal violet. The biofilm formation ability was monitored by measuring $\mathrm{OD}_{630}$ value at $12,24,36,48$, and $60 \mathrm{~h}$ post incubation. Each strain was tested in 6 wells in a 96-well microtiter plate. Y-axis meant the relative biofilm value normalized as the $\mathrm{OD}_{600}$ value of the bacterial cultures. All above assays were performed in triplicate for three times. Bars represent the mean \pm standard deviation of three independent experiments. Statistical analyses were performed using the two-way ANOVA. ${ }^{*} p<0.05$, ${ }^{* *} p<0.01$, and ${ }^{* * *} p<0.001$ represent increasing degrees of significant difference.

\section{Effect of luxS Gene on H. parasuis Adherence Ability in PK-15 Cells}

To determine whether luxS gene interacted with host cells, porcine kidney cells (PK-15 cells) were utilized to compare the adherence ability of HPS2, $\Delta$ luxS, and C-luxS strains. After incubation at $37^{\circ} \mathrm{C}$ for $2 \mathrm{~h}$, about $33 \%$ HPS2 strains adhered to pk- 15 cells, while only about $0.28 \% \Delta$ luxS strains adhered to pk15 cells. Thus, the adherence ability of HPS2 strain was more than 100 times higher than that of $\Delta$ luxS strain. Meanwhile, the adherence ability of C-luxS strain was about $1.4 \%$, which was 5 times as high as that of $\Delta$ luxS strain. Therefore, adherence ability was partially recovered in the complemented strain (Figure 8).

\section{LuxS Gene Was Associated With the Virulence of $\boldsymbol{H}$. parasuis}

The effect of the luxS gene on virulence was evaluated using Balb/C mouse model i.p. injected with various doses of HPS2,
$\Delta$ luxS, and C-luxS strains. The mortality of mice was observed within 14 days after challenging. Depression, rough coat, tremble, and prostration were observed in high dose group mice after $6 \mathrm{~h}$ of injection, and most of mice died within first 3 days. The final $\mathrm{LD}_{50}$ value of HPS2 was found to be $4.46 \times 10^{8} \mathrm{CFU}$, which the value for the same effect in $\Delta$ luxS strain was $4.28 \times$ $10^{9} \mathrm{CFU}$, which was 9.59 times as high as the value required by HPS2 strain, indicating that the virulence of $\Delta$ luxS strain significantly reduced, compared with that of HPS2 strain. The virulence of complemented mutant strain C-luxS $\left(8.89 \times 10^{8}\right.$ CFU) was partially restored (Table 2).

\section{The Tissue Burdens of HPS2, $\Delta$ luxS, and C-IuxS Strains}

To further evaluate the virulence of HPS2, $\Delta$ luxS, and C-luxS strains, viable bacteria in infected mice organs were counted. As seen in Figure 9, bacteria were isolated from all heart, liver, spleen, lung and kidney tissues in three kinds of group mice. The number of bacteria in the lung was the largest, follow by spleen, kidney, liver, and heart, and the bacteria decreased gradually from the first day to the last day. Bacterial counts of $\Delta$ luxS-infected mice were significantly decreased compared with those of HPS2 or C-luxS-infected mice in all collected tissues (Figure 9), suggesting the colonization ability of HPS2 and C-luxS strains was obviously stronger than $\Delta$ luxS strain.

\section{DISCUSSION}

LuxS amino acid sequences were grouped into three major distinct clusters in the phylogenetic tree in the previous studies (Sun et al., 2004; Rao et al., 2016), and the luxS quorum sensing system was reported to be present in approximately half of all sequenced bacterial genomes (Waters and Bassler, 2004). Therefore, luxS gene could play an important identification role in species recognition to some extent. LuxS/AI-2 system was reported to exist in A. actinomycetemcomitans, A. pleuropneumoniae, $H$. influenzae, and Mannheimia haemolytica of the family of Pasteurellaceae. LuxS inactivation affected the physiological features and/or virulence of the abovementioned strains (Fong et al., 2003; Daines et al., 2005; van der Vinne et al., 2005; James et al., 2006b; Li et al., 2008). 
A1

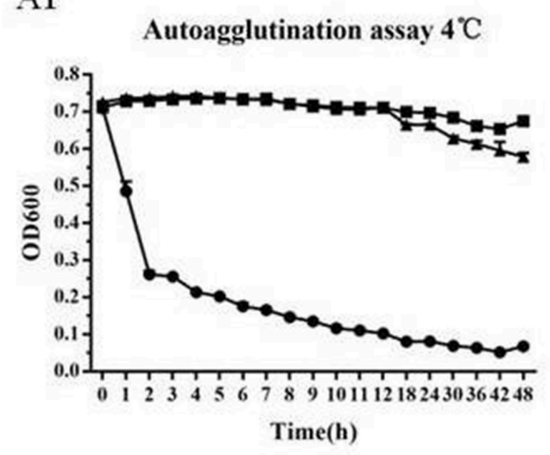

B1

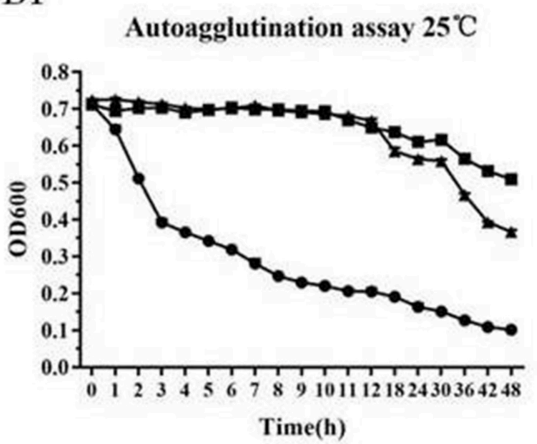

C1

Autoagglutination assay $37^{\circ} \mathrm{C}$

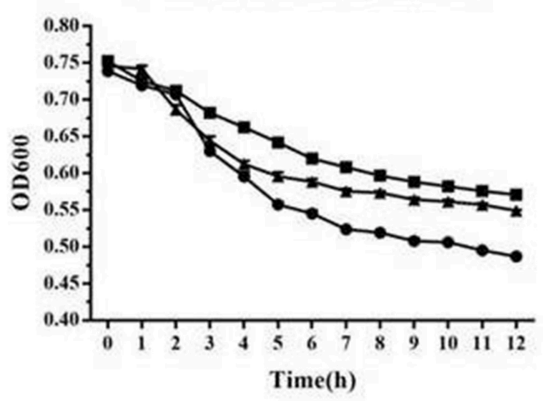

A2

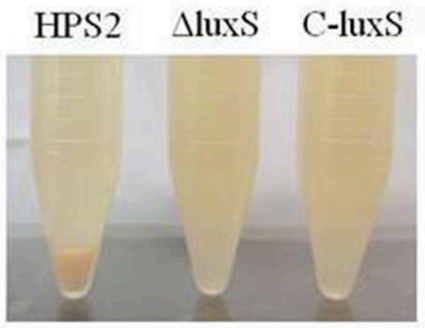

B2

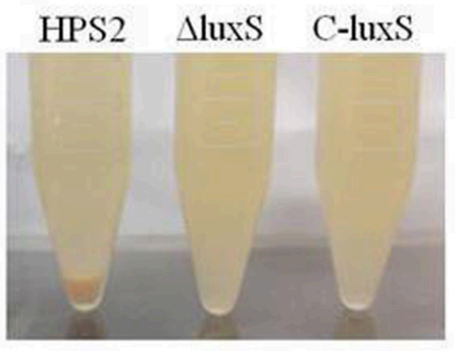

C2

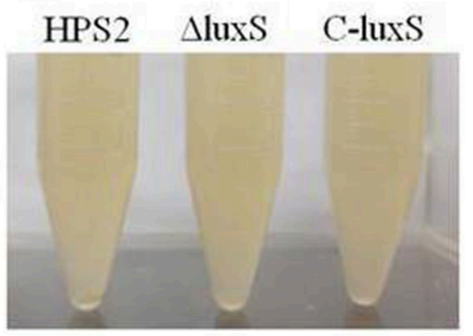

FIGURE 6 | Autoagglutination ability of HPS2, $\Delta$ luxS, and C-luxS strains at different temperatures. Overnight cultured bacteria were diluted to an OD 600 value near 0.75. The $0.2 \mathrm{~mL}$ of the upper liquid was taken to measure $\mathrm{OD}_{600}$ value from 1 to $24 \mathrm{~h}$ post-inoculation at $4^{\circ} \mathrm{C}(\mathbf{A} 1, \mathbf{A} 2), 25^{\circ} \mathrm{C}(\mathbf{B 1}, \mathbf{B 2})$, and $37^{\circ} \mathrm{C}(\mathbf{C} 1, \mathbf{C} 2)$. All of the above assays were performed in triplicate for three times. Bars represent the mean \pm standard deviation of three independent experiments. Statistical analyses were performed using the two-way ANOVA.

In this study, luxS genes from the genomes of 15 kinds of standard reference strains of $H$. parasuis were identified and their homology was highly conserved, compared with that of luxS genes of Pasteurella strains, indicating that luxS gene in $H$. parasuis may play a similar role in other strains.

Mutant strain $\Delta$ luxS and complemented strain C-luxS were constructed and polarity effect also been verified to make sure that the change in function of $\Delta$ luxS strain was only attributed to luxS gene, rather than other upstream or downstream genes. This study found that the growth characteristics of the examined strains were similar except that the growth rate of C-luxS strain was about $2 \mathrm{~h}$ slower than that of HPS2 and $\Delta$ luxS strains, and that all strains exhibited a decrease in $\mathrm{OD}_{600}$ value after 18 (HPS2 and $\Delta$ luxS strains) or 20 (C-luxS strain) hours of culturation in $\mathrm{T} / \mathrm{V} / \mathrm{S}$ medium, rather than remained stable after reaching stationary phase, and which might be due to the dissolution of bacteria in nutrient deficient medium.

The results of AI-1 and AI-2 detection assay showed that $H$. parasuis only produced AI-2 molecule and that no AI-1 molecule could be detected in the supernatant of 15 kinds of standard reference strains of $H$. parasuis. In addition, when luxS gene was deleted from HPS2, the luminescence value was almost the same with that detected in the negative group (Figure 2C). Based on it, it could be inferred that luxS/AI-2 might be probably the 

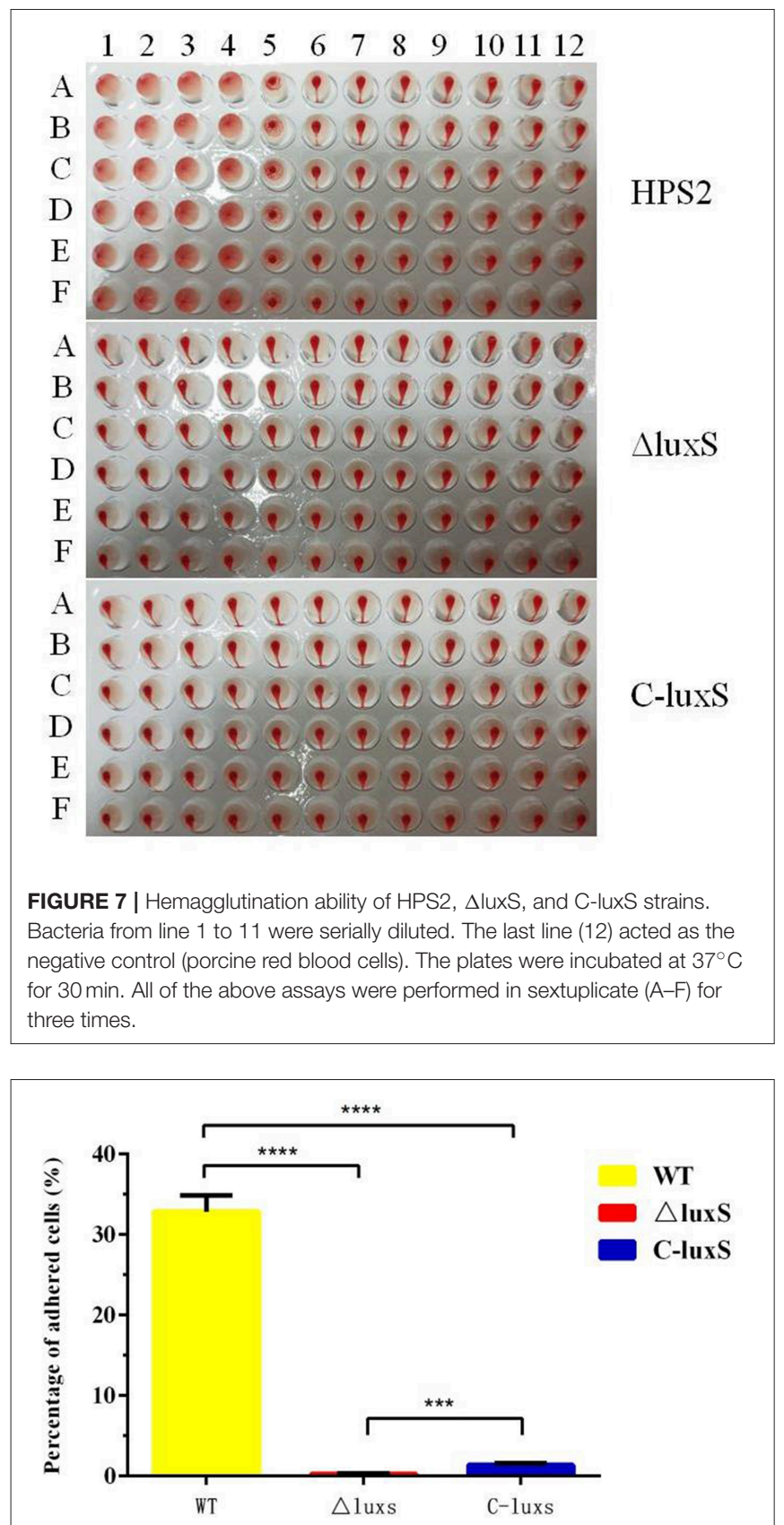

FIGURE 8 | Adherence ability of HPS2, $\Delta$ luxS, and C-luxS strains in pk-15 cells. The percentage of adhered cells represents bacteria adhered to cells in each well of a 24-well plate. Culture plates were incubated for up to $2 \mathrm{~h}$ at $37^{\circ} \mathrm{C}$. Error bars represent the standard deviation of three independent experiments performed in triplicate. Statistical analyses were performed using the two-way ANOVA. ${ }^{* \star *} p<0.001$ and ${ }^{* \star \star *} p<0.0001$ represent higher and the highest degree of significant difference, respectively.

only kind of quorum sensing system existing in $H$. parasuis, and that AI-2 might also be a kind of common molecules in all $H$. parasuis strains. But the expression levels of different serotype strains were different and could not reach the level expressed by the reporter strain $V$. harveyi BB170 (Figures 2B, C), which might be due to the fact that the structure of AI-2 was different
TABLE 2 | LD 50 value of HPS2, $\Delta$ luxS and C-luxS strains in mice.

\begin{tabular}{|c|c|c|c|c|}
\hline Strains & $\begin{array}{l}\text { Challenge dose } \\
\text { (CFU) }\end{array}$ & $\begin{array}{l}\text { Percent of dead } \\
\text { mice }(\%)\end{array}$ & $\begin{array}{l}\text { Value of } \\
\text { LD }_{50} \text { CFU }\end{array}$ & $\begin{array}{l}\text { Fold } \\
\text { change }^{*}\end{array}$ \\
\hline \multirow[t]{4}{*}{ HPS2 } & $9.63 \times 10^{7}$ & $0(0 / 10)$ & $4.46 \times 10^{8}$ & 1 \\
\hline & $2.08 \times 10^{8}$ & $20(2 / 10)$ & & \\
\hline & $4.47 \times 10^{8}$ & $30(3 / 10)$ & & \\
\hline & $9.63 \times 10^{8}$ & $100(10 / 10)$ & & \\
\hline \multirow[t]{4}{*}{$\Delta$ luxS } & $7.57 \times 10^{8}$ & $0(0 / 10)$ & $4.28 \times 10^{9}$ & 9.59 \\
\hline & $1.55 \times 10^{9}$ & $0(0 / 10)$ & & \\
\hline & $3.34 \times 10^{9}$ & $20(2 / 10)$ & & \\
\hline & $7.57 \times 10^{9}$ & $90(9 / 10)$ & & \\
\hline \multirow[t]{4}{*}{ C-luxS } & $5.83 \times 10^{8}$ & $0(0 / 10)$ & $8.89 \times 10^{8}$ & 1.99 \\
\hline & $1.17 \times 10^{9}$ & $90(9 / 10)$ & & \\
\hline & $2.25 \times 10^{9}$ & $100(10 / 10)$ & & \\
\hline & $5.83 \times 10^{9}$ & $100(10 / 10)$ & & \\
\hline
\end{tabular}

${ }^{\star}$ Fold change normalized to the wild-type strain (HPS2).

in various species to some degree (Miller et al., 2004). As seen in Figure 2A, the amount of AI-2 molecule reached its maximum in early stationary phase, and it decreased sharply after stationary phase (Figure 2A). The AI-2 molecule variation pattern of HPS2 was similar to that of M. haemolytica A1 (Malott and Lo, 2002), C. perfringens (Ohtani et al., 2002), and Streptococcus mutant (Merritt et al., 2003). However, in many other species, such as A. pleuropneumoniae (Li et al., 2008), A. actinomycetemcomitans (Fong et al., 2001), enterohemorrhagic and enteropathogenic $E$. coli (Bowden and Li, 1997) and Porphyromonas gingivalis (James et al., 2006a), the amount of AI-2 molecule reached the maximum in exponential phase, suggesting that the function of AI-2 signal molecule might vary with different species.

In some strains, such as A. pleuropneumoniae, Streptococcus mutants, and $P$. gingivalis, luxS gene was verified to be associated with stress response in previous studies (Wen and Burne, 2004; Yuan et al., 2005; Li et al., 2008; Ma et al., 2017). In the heat shock assay, we found $\Delta$ luxS strain showed weak resistance to high temperature $\left(48^{\circ} \mathrm{C}\right)$, which was consistent with another finding of our study that the growth activity of $\Delta$ luxS strain was inhibited under $40^{\circ} \mathrm{C}$. In addition, our study revealed that the ability of $\triangle$ luxS strain against oxidative stress decreased, which agreed with the previous study results of $\Delta \operatorname{luxS}$ strain of $A$. pleuropneumoniae (Li et al., 2008). Whereas, our result was in contrast with the previous study of $\Delta$ luxS strain of Streptococcus mutans (Wen and Burne, 2004) and P. gingivalis (Yuan et al., 2005). To explore the reasons why significant differences in growth characteristic and the ability to tolerate stress resistance were observed between HPS2 and $\triangle$ luxS, the expression level of some transcriptional regulatory genes was quantified, based on the reports that $h t r A$ is a kind of very important heat shock induced serine protease (Pallen and Wren, 2010), and that the growth characteristic of its mutant strain is inhibited at high temperature (Zhang et al., 2016). The quantitative results showed that the amount of mRNA of $h t r A$ gene in $\triangle$ luxS strain was obviously lower than that of HPS2 and C-luxS strains, which may explained why $\Delta$ luxS strain displayed the deficient growth 

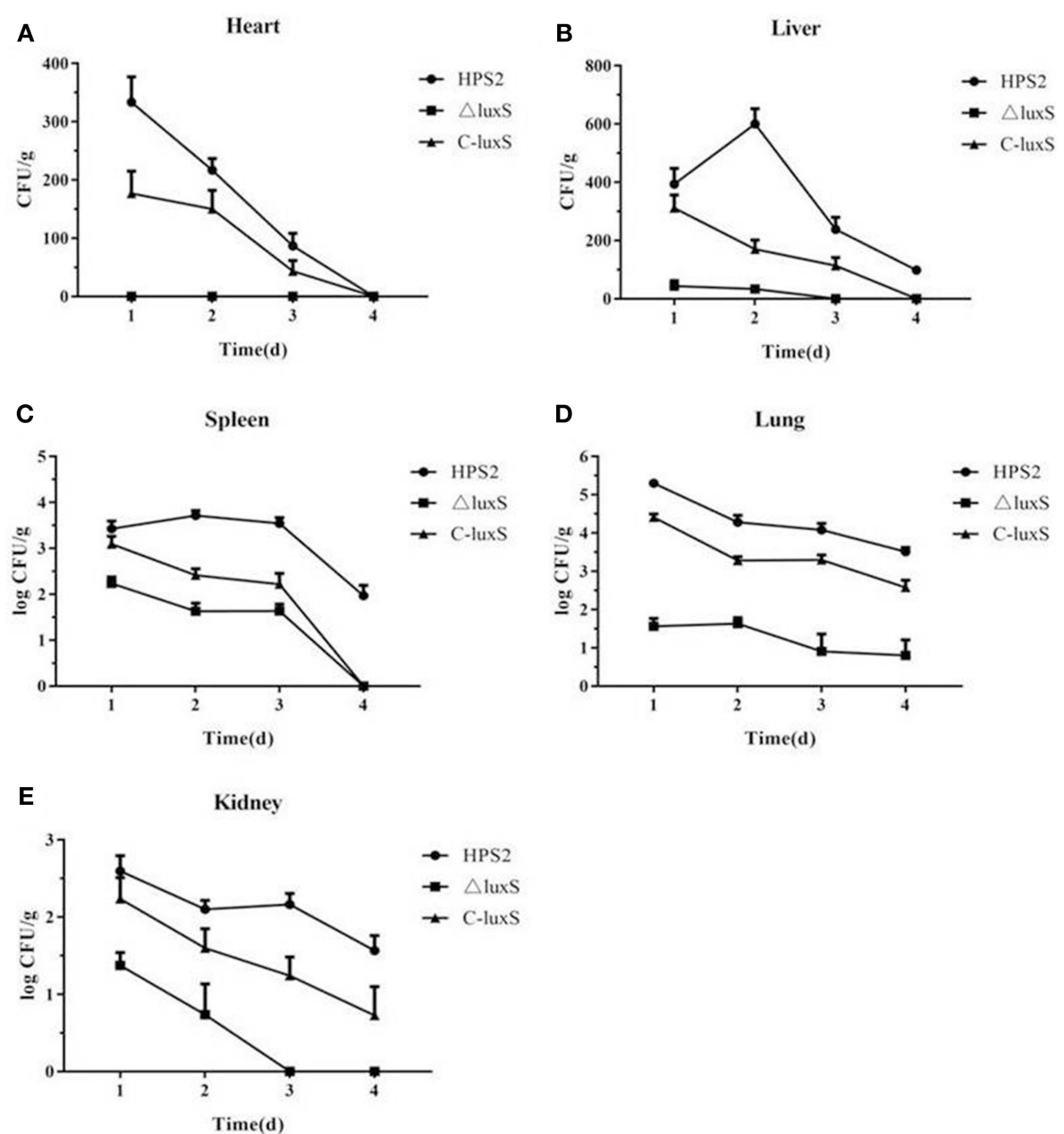

FIGURE 9 | Bacterial distribution in heart (A), liver (B), spleen (C), lung (D), and kidney (E) of infected mice. The number of colonies was counted from day1 to day 4 post infection, and the results were expressed as CFU/1 $\mathrm{g}$ for all tissue samples. Error bars represent the standard deviation from three independent experiments performed in triplicate.

characteristic at high temperature and weak resistance to stress response (Supplementary Figure 2).

The wild-type standard reference strain HPS2 was reported to have weak ability to form biofilm (Jin et al., 2006). In this study, a small amount of biofilm was observed, when HPS2 was cultured in $\mathrm{T} / \mathrm{V} / \mathrm{S}$ medium over $24 \mathrm{~h}$, which may due to the difference of culture conditions (Figure 5). As reported in previous study, the vast majority of bacteria in natural and clinical environments exist in form of biofilm and not as the free-living or "planktonic" cells (Kaplan and Mulks, 2005). Biofilm also plays a key role in the pathogenesis of many bacterial infections (Parsek and Singh, 2003). In this study, AI-2 molecular synthesized by luxS gene was found to have inhibited the biofilm formation. which was consistent with the previous studies of A. pleuropneumoniae (Li et al., 2008, 2011) and H. influenzae (Daines et al., 2005; Armbruster et al., 2009, 2011; Pang et al., 2018). But other previous studies reported that AI-2 molecular could enhance the ability of biofilm formation in some bacteria, such as S. suis (Merritt et al., 2003), Staphylococcus aureus (Yu et al., 2012), and Pseudomonas aeruginosa (Sakuragi and Kolter, 2007), It may be attributed to the complexity of biofilm formation involving the multifactors which participated in adherence, metabolism, quorum sensing, and the stress response, and other processes (Hasona et al., 2007). On the other hand, $h t r A$ was found to have inhibited the formation of biofilm in $H$. parasuis (Zhang et al., 2016). Meanwhile, our quantitative results of $h t r A$ in HPS2, $\Delta$ luxS, and C-luxS strains supported the result of previous study.

It has been reported that the abilities of autoagglutination, hemagglutination, and adherence were virulence-associated markers (Janda et al., 1987; Fitzgerald et al., 1999; Liu et al., 2016). The adherence of bacteria to host cell surfaces was an essential determinant for bacterial colonization and cellular invasion which contributed to breaching the cell barriers, persistent infection in the host, ultimately resulting in systemic disease (Vahle et al., 1997). This study found that the abilities of autoagglutination, hemagglutination, and adherence of $\Delta$ luxS strain were sharply decreased, compared with those of HPS2 strain, which, in turn, proved the decrease of virulence in $\Delta$ luxS 
strain. Similar results were also found in C. jejuni strain. The autoagglutination ability of luxS mutant decreased, compared with that of wild-type strain (Jeon et al., 2003). Meanwhile, the variation pattern of hemagglutination and adherence abilities in $\Delta$ luxS strain was found to be the same with that of Haemophilus ducreyi and Actinobacillus pleuropneumoniae, respectively (Labandeirarey et al., 2010; Liu et al., 2016). However, the growth characteristic at $40^{\circ} \mathrm{C}$ and abilities of autoagglutination, hemagglutination, and adherence could not be absolutely rescued in complemented strain C-luxS, which may be due to the difference of transcriptional level of luxS gene in wild-type and complemented strains, in turn, its transcriptional level of related genes would also be changed. So, compared with wild-type strain, the balance of regulatory network in complemented strain was changed. On the other hand, the detailed relationship between autoagglutination, hemagglutination, and adherence remains unclear. Therefore, their complicated regulatory network remains to be further investigated.

LuxS gene was previously identified as a virulence determinant contributing to intracellular survival in A. pleuropneumoniae (Li et al., 2008), H. influenzae (Daines et al., 2005), and Streptococcus (Wen and Burne, 2004; Ma et al., 2017). To further evaluate the role of $\operatorname{luxS}$ gene in the pathogenesis of $H$. parasuis in vivo, $\mathrm{LD}_{50}$ and tissue burdens of bacteria in mice organs were measured. $\mathrm{LD}_{50}$ experiment showed that the virulence of $\Delta$ luxS strain attenuated about 10 times. The $\Delta$ luxS strains were found to have sharply decreased in heart, liver, spleen, lung, and kidney, compared with HPS2. Lung is the major target organ for $H$. parasuis to reside. The largest amount of bacteria were separated from it. As the time went on, the total amount of HPS2, $\Delta$ luxS, and C-luxS strains in organs were obviously declined in the tissues, suggesting that the colonization ability and virulence of $\Delta$ luxS strain decreased.

\section{REFERENCES}

Armbruster, C. E., Hong, W., Pang, B., Dew, K. E., Juneau, R. A., Byrd, M. S., et al. (2009). LuxS promotes biofilm maturation and persistence of nontypeable haemophilus influenzae in vivo via modulation of lipooligosaccharides on the bacterial surface. Infect. Immunity. 77, 4081-4091. doi: 10.1128/IAI.00320-09

Armbruster, C. E., Pang, B., Murrah, K., Juneau, R. A., Perez, A. C., and Weimer, K. E. (2011). RbsB (NTHI_0632) mediates quorum signal uptake in nontypeable Haemophilus influenzae strain 86-028NP. Mol. Microbiol. 82, 836-850. doi: 10.1111/j.1365-2958.2011.07831.x

Bassler, B. L., Greenberg, E. P., and Stevens, A. M. (1997). Cross-species induction of luminescence in the quorum-sensing bacterium Vibrio harveyi. J. Bacteriol. 179, 4043-4045. doi: 10.1128/jb.179.12.4043-4045.1997

Bowden, G. H., and Li, Y. H. (1997). Nutritional Influences on biofilm development. Adv. Dental Res. 11, 81-99. doi: 10.1177/08959374970110012101

Chen, F., Knutson, T. P., Porter, R. E., Ciarlet, M., Mor, S. K., and Marthaler, D. G. (2017). Genome characterization of Turkey Rotavirus G strains from the United States identifies potential recombination events with human Rotavirus B strains. J. Gen. Virol. 98:2931. doi: 10.1099/jgv.0.000963

Daines, D. A., Bothwell, M., Furrer, J., Unrath, W., Nelson, K., Jarisch, J., et al. (2005). Haemophilus influenzae luxS mutants form a biofilm and have increased virulence. Microb. Pathog. 39, 87-96. doi: 10.1016/j.micpath.2005.06.003

\section{CONCLUSIONS}

In summary, we constructed the luxS deletion mutant and its complemented strain from $H$. parasuis serovar 2, and preliminarily investigated the effects of luxS gene on several virulence-associated properties. The comparison of $\Delta$ luxS with HPS2 and C-luxS strains revealed that $\operatorname{luxS}$ gene was related to phenotypic characteristics and biological abilities including growth characteristic, stress response, quorum sensing, biofilm formation, autoagglutination, hemagglutination, adherence, and virulence-associated $\mathrm{LD}_{50}$ and tissue burdens of bacteria. This study provides an insight into the role of the luxS gene in the pathogenesis of $H$. parasuis infection.

\section{AUTHOR CONTRIBUTIONS}

BZ and QH: conceptualization and writing-review \& editing; $\mathrm{BZ}$ and $\mathrm{XK}$ : data curation; $\mathrm{BZ}, \mathrm{XZ}$, and $\mathrm{YZ}$ : formal analysis; $\mathrm{QH}$ : funding acquisition; $\mathrm{BZ}, \mathrm{XK}$, and $\mathrm{YZ}$ : investigation; $\mathrm{BZ}, \mathrm{XK}$, $\mathrm{YZ}$, and QH: methodology; QH: project administration; FC, XZ, and GC: software; QH: supervision; BZ, GC, WZ, JL, and LZ: visualization; BZ: writing —original draft.

\section{ACKNOWLEDGMENTS}

This research was supported by China Agriculture Research System (No. CARS-35).

\section{SUPPLEMENTARY MATERIAL}

The Supplementary Material for this article can be found online at: https://www.frontiersin.org/articles/10.3389/fcimb. 2019.00062/full\#supplementary-material

Fitzgerald, M., Murphy, S., Mulcahy, R., Keane, C., Coakley, D., and Scott, T. (1999). Tissue culture adherence and haemagglutination characteristics of Moraxella (Branhamella) catarrhalis. Pathog. Dis. 24, 105-114.

Fong, K. P., Chung, W. O., Lamont, R. J., and Demuth, D. R. (2001). Intra- and interspecies regulation of gene expression by actinobacillus actinomycetemcomitans LuxS. Infect. Immunity 69:7625. doi: 10.1128/IAI.69.12.7625-7634.2001

Fong, K. P., Gao, L., and Demuth, D. R. (2003). luxS and arcB control aerobic growth of Actinobacillus actinomycetemcomitans under iron limitation. Infect. Immunity. 71, 298-308. doi: 10.1128/IAI.71.1.298-3 08.2003

Hardie, K. R., and Heurlier, K. (2008). Establishing bacterial communities by 'word of mouth': LuxS and autoinducer 2 in biofilm development. Nat. Rev. Microbiol. 6:635. doi: 10.1038/nrmicro1916

Hasona, A., Zuobihasona, K., Crowley, P. J., Abranches, J., Ruelf, M. A., Bleiweis, A. S., et al. (2007). Membrane composition changes and physiological adaptation by Streptococcus mutans signal recognition particle pathway mutants. J. Bacteriol. 189:1219. doi: 10.1128/JB.01146-06

Huang, J., Wang, X., Cao, Q., Feng, F., Xu, X., and Cai, X. (2016). ClpP participates in stress tolerance and negatively regulates biofilm formation in Haemophilus parasuis. Vet. Microbiol. 182, 141-149. doi: 10.1016/j.vetmic.2015.11.020

James, C. E., Hasegawa, Y., Park, Y., Yeung, V., Tribble, G. D., Kuboniwa, M., et al. (2006a). LuxS involvement in the regulation of genes coding for hemin and iron 
acquisition systems in Porphyromonas gingivalis. Infect. Immun. 感染与免疫 志 74, 3834-3844. doi: 10.1128/IAI.01768-05

James, D. A., Shao, H. J., Lamont, R. J., and Demuth, D. R., et al. (2006b) The Actinobacillus actinomycetemcomitans ribose binding protein $\mathrm{RbsB}$ interacts with cognate and heterologous autoinducer 2 signals. Infect. Immunity. 74, 4021-4029. doi: 10.1128/IAI.01741-05

Janda, J. M., Oshiro, L. S., Abbott, S. L., and Duffey, P. S. (1987). Virulence markers of mesophilic aeromonads: association of the autoagglutination phenomenon with mouse pathogenicity and the presence of a peripheral cell-associated layer. Infect. Immunity 55, 3070-3077.

Jeon, B., Itoh, K., Misawa, N., and Ryu, S. (2003). Effects of quorum sensing on flaA transcription and autoagglutination in Campylobacter jejuni. Microbiol. Immunol. 47, 833-839. doi: 10.1111/j.1348-0421.2003.tb03449.x

Jin, H., Zhou, R., Kang, M., Luo, R., Cai, X., and Chen, H. (2006). Biofilm formation by field isolates and reference strains of Haemophilus parasuis. Vet. Microbiol. 118, 117-123. doi: 10.1016/j.vetmic.2006.07.009

Kaplan, J. B., and Mulks, M. H. (2005). Biofilm formation is prevalent among field isolates of Actinobacillus pleuropneumoniae. Vet. Microbiol. 108, 89-94. doi: 10.1016/j.vetmic.2005.02.011

Kendall, M. M., and Sperandio, V. (2007). Quorum sensing by enteric pathogens. Curr. Opin. Gastroenterol. 23, 10-15. doi: 10.1097/MOG.0b013e3280118289

Kielstein, P., and Rapp-Gabrielson, V. J. (1992). Designation of 15 serovars of Haemophilus parasuis on the basis of immunodiffusion using heat-stable antigen extracts. J. Clin. Microbiol. 30, 862-865.

Labandeirarey, M., Brautigam, C. A., and Hansen, E. J. (2010). Characterization of the CpxRA regulon in Haemophilus ducreyi. Infect. Immunity. 78, 4779-4791. doi: 10.1128/IAI.00678-10

Li, G., Xie, F., Li, J., Liu, J., Li, D., Zhang, Y., et al. (2017). Identification of novel Haemophilus parasuis serovar 5 vaccine candidates using an immunoproteomic approach. J. Proteom. 163, 111-117. doi: 10.1016/j.jprot.2017.05.014

Li, L., Xu, Z., Zhou, Y., Li, T., Sun, L., Chen, H., et al. (2011). Analysis on Actinobacillus pleuropneumoniae LuxS regulated genes reveals pleiotropic roles of LuxS/AI-2 on biofilm formation, adhesion ability and iron metabolism. Microb. Pathog. 50, 293-302. doi: 10.1016/j.micpath.2011.02.002

Li, L., Zhou, R., Li, T., Kang, M., Wan, Y., Xu, Z., et al. (2008). Enhanced biofilm formation and reduced virulence of Actinobacillus pleuropneumoniae luxS mutant. Microb. Pathog. 45, 192-200. doi: 10.1016/j.micpath.2008.05.008

Liu, H., Qiao, X., Zeng, Q., and Zhao, Z. (2016). Haemophilus parasuis vaccines. Vet. Immunol. Immunopathol. 180, 53-58. doi: 10.1016/j.vetimm.2016.09.002

Ma, Y., Hao, L., Ke, H., Liang, Z., Ma, J., Liu, Z., et al. (2017). LuxS/AI-2 in Streptococcus agalactiae reveals a key role in acid tolerance and virulence. Res. Vet. Sci. 115, 501-507. doi: 10.1016/j.rvsc.2017.07.032

Malott, R. J., and Lo, R. Y. C. (2002). Studies on the production of quorum-sensing signal molecules in Mannheimia haemolytica A1 and other Pasteurellaceae species. Fems Microbiol. Lett. 206, 25-30. doi: 10.1111/j.1574-6968.2002.tb10981.x

Merritt, J., Qi, F., Goodman, S. D., Anderson, M. H., and Shi, W. (2003). Mutation of luxS affects biofilm formation in Streptococcus mutans. Infect. Immunity. 71, 1972-1979. doi: 10.1128/IAI.71.4.1972-1979.2003

Miller, M. B., and Bassler, B. L. (2001). Quorum sensing in bacteria. Ann. Rev. Microbiol. 55, 165-199. doi: 10.1146/annurev.micro.55.1.165

Miller, S. T., Xavier, K. B., Campagna, S. R., Taga, M. E., Semmelhack, M. F., Bassler, B. L., et al. (2004). Salmonella typhimurium recognizes a chemically distinct form of the bacterial quorum-sensing signal AI-2. Mol. Cell 15, 677-687. doi: 10.1016/j.molcel.2004.07.020

Nealson, K. H., and Hastings, J. W. (1979). Bacterial bioluminescence: its control and ecological significance. Microbiol. Rev. 43, 496-518.

Ohtani, K., Hayashi, H., and Shimizu, T. (2002). The luxS gene is involved in cellcell signalling for toxin production in Clostridium perfringens. Mol. Microbiol. 44, 171-179. doi: 10.1046/j.1365-2958.2002.02863.x

Oliveira, S., Galina, L., and Pijoan, C. (2001). Development of a PCR Test to diagnose Haemophilus parasuis infections. J. Vet. Diagn. Invest. 13, 495-501. doi: $10.1177 / 104063870101300607$

Pallen, M. J., and Wren, B. W. (2010). The HtrA family of serine proteases. Mol. Microbiol. 26, 209-221. doi: 10.1046/j.1365-2958.1997.5601928.x

Pang, B., Armbruster, C. E., Foster, G., Learman, B. S., Gandhi, U., Swords, W. E. (2018). Autoinducer 2 (AI-2) production by nontypeable $86-028 \mathrm{NP}$ promotes expression of a predicted glycosyltransferase that is a determinant of biofilm maturation, prevention of dispersal, and persistence in vivo. Infect. Immunity 86, e00506-18. doi: 10.1128/IAI.00506-18

Parsek, M. R., and Singh, P. K. (2003). Bacterial biofilms: an emerging link to disease pathogenesis. Ann. Rev. Microbiol. 57, 677-701. doi: 10.1146/annurev.micro.57.030502.090720

Pearson, M. M., Lafontaine, E. R., Wagner, N. J., and Hansen, E. J. (2002). A hag mutant of Moraxella catarrhalis strain $\mathrm{O} 35 \mathrm{E}$ is deficient in hemagglutination, autoagglutination, and immunoglobulin D-binding activities. Infect. Immunity 70, 4523-4533. doi: 10.1128/IAI.70.8.4523-4533.2002

Rao, R. M., Naseer, P. S., and Ramanathan, S. (2016). Genome-wide survey and phylogeny of S-Ribosylhomocysteinase (LuxS) enzyme in bacterial genomes. BMC Genom. 17:742. doi: 10.1186/s12864-016-3002-x

Sakuragi, Y., and Kolter, R. (2007). Quorum-sensing regulation of the biofilm matrix genes (pel) of Pseudomonas aeruginosa. J. Bacteriol. 189, 5383-5386. doi: 10.1128/JB.00137-07

Stepanovic, S., Vukovic, D., Dakic, I., Savic, B., and Svabicvlahovic, M. (2000). A modified microtiter-plate test for quantification of staphylococcal biofilm formation. J. Microbiol. Methods 40, 175-179. doi: 10.1016/S0167-7012(00)00122-6

Sun, J., Daniel, R., Wagnerdöbler, I., and Zeng, A. P. (2004). Is autoinducer-2 a universal signal for interspecies communication: a comparative genomic and phylogenetic analysis of the synthesis and signal transduction pathways. BMC Evol. Biol. 4:36. doi: 10.1186/1471-2148-4-36

Vahle, J. L., Haynes, J. S., and Andrews, J. J. (1997). Interaction of Haemophilus parasuis with nasal and tracheal mucosa following intranasal inoculation of cesarean derived colostrum deprived (CDCD) swine. Can. J. Vet. Res. 14, 200-206.

van der Vinne, A. N., Lo, R. Y., and Shewen, P. E. (2005). Construction and analysis of a Mannheimia haemolytica A1 luxS mutant. Vet. Microbiol. 110, 53-66. doi: 10.1016/j.vetmic.2005.06.011

Vanier, G., Segura, M., Friedl, P., Lacouture, S., and Gottschalk, M. (2004). Invasion of porcine brain microvascular endothelial cells by Streptococcus suis Serotype 2. Infect. Immunity 72, 1441-1449. doi: 10.1128/IAI.72.3.1441-1449.2004

Vanier, G., Szczotka, A., Friedl, P., Lacouture, S., Jacques, M., and Gottschalk, M. (2006). Haemophilus parasuis invades porcine brain microvascular endothelial cells. Microbiology 152, 135-142. doi: 10.1099/mic.0.28312-0

Wang, X., Li, X., and Ling, J. (2017). Streptococcus gordonii LuxS/autoinducer2 quorum-sensing system modulates the dual-species biofilm formation with Streptococcus mutans. J. Basic Microbiol. 57, 605-616. doi: 10.1002/jobm.201700010

Wang, X., Xu, X., Wu, Y., Li, L., Cao, R., Cai, X., et al. (2013). Polysaccharide biosynthesis protein CapD is a novel pathogenicity-associated determinant of Haemophilus parasuis involved in serum-resistance ability. Vet. Microbiol. 164, 184-189. doi: 10.1016/j.vetmic.2013.01.037

Wang, Y., Zhang, W., Wu, Z., Zhu, X., and Lu, C. (2011). Functional analysis of luxS in Streptococcus suis reveals a key role in biofilm formation and virulence. Vet. Microbiol. 152, 151-160. doi: 10.1016/j.vetmic.2011.04.029

Waters, C. M., and Bassler, B. L. (2004). Quorum sensing: cell-to-cell communication in bacteria. Annu. Rev. Cell. Dev. Biol. 21, 319-346. doi: 10.1146/annurev.cellbio.21.012704.131001

Wen, Z. T., and Burne, R. A. (2004). LuxS-mediated signaling in Streptococcus mutans is involved in regulation of acid and oxidative stress tolerance and biofilm formation. J. Bacteriol. 186, 2682-2691. doi: 10.1128/JB.186.9.2682-2691.2004

Xie, F., Zhang, Y., Li, G., Zhou, L., Liu, S., and Wang, C. (2013). The ClpP protease is required for the stress tolerance and biofilm formation in Actinobacillus pleuropneumoniae. PLoS ONE 8:e53600. doi: 10.1371/journal.pone.00 53600

Yu, D., Zhao, L., Xue, T., and Sun, B. (2012). Staphylococcus aureus autoinducer-2 quorum sensing decreases biofilm formation in an icaR -dependent manner. BMC Microbiol. 12:288. doi: 10.1186/1471-2180-12-288

Yuan, L., Hillman, J. D., and Progulskefox, A. (2005). Microarray analysis of quorum-sensing-regulated genes in Porphyromonas gingivalis. Infect. Immunity. 73, 4146-4154. doi: 10.1128/IAI.73.7.4146-4154.2005

Zhang, B., He, Y., Xu, C., Xu, L., Feng, S., Liao, M., et al. (2012). Cytolethal distending toxin (CDT) of the Haemophilus parasuis SC096 strain contributes to serum resistance and adherence to and invasion of PK-15 and PUVEC cells. Vet. Microbiol. 157, 237-242. doi: 10.1016/j.vetmic.2011.12.002 
Zhang, B., Yu, Y., Zeng, Z., Ren, Y., and Yue, H. (2014). Deletion of the rfaE gene in Haemophilus parasuis SC096 strain attenuates serum resistance, adhesion and invasion. Microb. Pathog. 74, 33-37. doi: 10.1016/j.micpath.2014.07.006

Zhang, L., Li, Y., Wen, Y., Lau, G. W., Huang, X., Wu, R., et al. (2016). HtrA is important for stress resistance and virulence in Haemophilus parasuis. Infect. Immunity. 84, 2209-2219. doi: 10.1128/IAI.00147-16

Zhao, L., Gao, X., Liu, C., Lv, X., Nan, J., and Zheng, S. (2017). Deletion of the vacJ gene affects the biology and virulence in Haemophilus parasuis serovar 5. Gene. 603, 42-53. doi: 10.1016/j.gene.2016.12.009

Zou, Y., Feng, S., Xu, C., Zhang, B., Zhou, S., Zhang, L., et al. (2013). The role of galU and galE of Haemophilus parasuis SC096 in serum resistance and biofilm formation. Vet. Microbiol. 162, 278-284. doi: 10.1016/j.vetmic.2012.08.006
Conflict of Interest Statement: The authors declare that the research was conducted in the absence of any commercial or financial relationships that could be construed as a potential conflict of interest.

Copyright (c) 2019 Zhang, Ku, Zhang, Zhang, Chen, Chen, Zeng, Li, Zhu and He. This is an open-access article distributed under the terms of the Creative Commons Attribution License (CC BY). The use, distribution or reproduction in other forums is permitted, provided the original author(s) and the copyright owner(s) are credited and that the original publication in this journal is cited, in accordance with accepted academic practice. No use, distribution or reproduction is permitted which does not comply with these terms. 